УДК 615.454 .12

РАЗРАБОТКА НОРМ КАЧЕСТВА, ИЗУЧЕНИЕ СТАБИЛЬНОСТИ И УСТАНОВЛЕНИЕ СРОКОВ ГОДНОСТИ КОСМЕЦЕВТИЧЕСКИХ ФОРМ ЛИМОННИКА КИТАЙСКОГО

\author{
М.С. Макиева, Ю.А. Морозов
}

Северо-Осетинский государственный университет имени К.Л. Хетагурова, г. Владикавказ

\title{
QUALITY NORMS DEVELOPMENT, STUDY OF STABILITY AND ESTABLISHMENT OF SHELF-LIFE OF COSMECEUTICAL FORMS OF SCHIZANDRA CHINENSIS
}

\section{M.S. Makieva, Yu.A. Morozov}

North Ossetian State University after K.L. Khetagurov

E-mail: makieva-marina@yandex.ru

В статье приводятся результаты экспериментальных исследований по разработке норм качества, изучению стабильности и установлению сроков годности космецевтических препаратов, содержащих лимонника китайского семян $\mathrm{CO}_{2}$-экстракт, с применением УФспектрофотометрии и хроматографических методов анализа. Установленные нормы качества могут быть рекомендованы в дальнейшем при составлении нормативной документации. Предположительный срок годности изучаемых салфеток составил 24 месяца.

Ключевые слова. лимонник китайский, салфетки, показатели качества, срок годности.

В настоящее время лекарственные растения находят все более широкое применение в официальной медицине, принимая во внимание знания и опыт медицины народной, этномедицины [10].

Еще на заключительных страницах весьма содержательной монографии А.А. Лебедева «Лимонник»» (1971г.), посвященной обобщению результатов экспериментального изучения и клинического применения одного из растений, широко применявшегося в народной ме-
There are results of experimental studies in the quality norms, stability study and establishment of shelf-life of cosmeceutical forms with $\mathrm{CO}_{2}$ extract of Schizandra chinensis seeds using UV spectrophotometry and chromatographic analysis methods. The quality norms established may be recommended for normative documentation stipulation in future. The approximate shelf-life for the napkins under study was 24 months.

Keywords: Schizandra chinensis, napkins, quality indices, shelf-life.

дицине Востока, - лимонника китайского и полученных из него препаратов, приводятся данные о «превращении лимонника из средства народной медицины в современное лекарство, имеющее широкий диапазон применения». Здесь же автор поднимает вопрос и о разработке «более рациональных препаратов лимонника», ссылаясь на сведения, что «в аптеках имеется только настойка» [6].

Спустя 44 года, то есть на сегодняшний день, в ассортименте современ- 
ных аптек (согласно данным Государственного реестра лекарственных средств (ЛС) [3]), можно также, по-прежнему, встретить лекарственные препараты (ЛП) лимонника китайского только в форме настойки, полученной из семян этого растения. Ассортимент биологически активных добавок к пище, как правило, многокомпонентных, содержащих экстракт лимонника китайского, значительно больше. Среди них преобладают препараты для перорального применения (таблетки, капсулы, гранулы, сиропы).

Анализируя научные работы российских исследователей, посвященные разработке ЛП на основе лимонника китайского за последние 10 лет, следует по праву отметить труды А.И. Зиновьева (2003 г.), А.С. Степанова (2004 г.), А.М. Власова $(2006$ г.) и Ф.Ш. Сатдаровой $(2009$ г.) [2, 3, 8, 9].

В 2000 году Минздравом России в качестве ЛС был зарегистрирован отечественный ЛП «Ликол», представляющий собой стандартизованное масло лимонника в мягких желатиновых капсулах. Согласно результатам исследований, «Ликол» обладает гепатопротекторной, антиоксидантной, антигипоксической, иммунотропной активностью и превосходит по эффективности настойку лимонника. Однако в данное время ЛП не зарегистрирован, так как не прошел процедуру перерегистрации и в настоящий момент не применяется [11].

Примерно в это же время отечественными учеными был получен полифенольный ЛП из гребней (осевая часть соцветия, освобожденная от ягод) лимонника китайского, запатентованный как гепатопротектор (патент № 2179031 приоритет от 19.10.2000 г.) и зарегистрированный под торговой маркой «Экликит» (2000721209 от 18.08.2000) [5].

Поэтому в настоящее время актуальным становится вопрос по обобщению уже имеющихся сведений и проведению расширенных экспериментальных исследований по комплексной переработке лимонника китайского с целью получения безотходной и/или малоотходной технологии получения сырья и вывод новых ЛП на его основе, на отечественный фармацевтический рынок.

В работах $[4,7]$ нами показаны результаты исследования, подтверждающие способность использовать лимонника китайского семян $\mathrm{CO}_{2}$-экстракт в качестве основного действующего компонента оригинальных косметических форм салфеток.

Целью настоящей работы является разработка норм качества, изучение стабильности и установление сроков годности салфеток на основе лимонника китайского семян $\mathrm{CO}_{2}$-экстракта.

Исследования по разработке норм качества, изучению стабильности и установлению сроков годности для салфеток с лимонника китайского семян $\mathrm{CO}_{2}$ экстрактом проводили с использованием материалов и оборудования на базе инновационно-технологического центра «Фармация» (Проект № 2.5.1. Программы стратегического развития СОГУ) и центра коллективного пользования «Физика и технологии наноструктур».

Подлинность салфеток с лимонника китайского семян $\mathrm{CO}_{2}$-экстрактом проводили, подтверждая наличие флавонолигнанов лимонника китайского, которые идентифицировали с использованием качественной реакции по образованию окрашенного комплекса с кислотой серной концентрированной (ХЧ, ГОСТ 420477 «ХИММЕД», Россия, г. Москва).

Для качественного и количественного анализа применялись хроматографические методы анализа: тонкослойная (ТCX; Sorbfil, ТУ 26-11-17-89) и высокоэффективная жидкостная (ВЭЖХ; Милихром А-02 ЗАО Институт хроматографии «ЭкоНова», г. Новосибирск, Россия) хроматография и УФ-спектофотометрия (ПЭ-5400УФ ,ООО «Экохим», Россия, г. Санкт-Петербург) с применением стандартных образцов: схизандрола А (ChromaDex ${ }^{\circledR}$, CDX-00019500-010, CША) и $\gamma$-схизандрина (ChromaDex ${ }^{\circledR}, \mathrm{CDX}$ 00019505-010, США).

Водородный показатель для разработанных салфеток определяли по об- 
щепринятой потенциометрической методике (рН-метр рН 150 ММ, № 5336, ТУ 4215-051-89650280-2009, ООО «Измерительная техника», г. Москва, Россия).

Установление сроков годности проводили на 3 опытных сериях по следующим критериальным показателям оценки качества: описание (внешний вид, цвет, запах), подлинность, водородный показатель, количественное определение, микробиологическая чистота. Образцы салфеток, полученные в лабораторных условиях и упакованные по 20 салфеток в плотно укупоренные полиэтиленовые контейнеры, хранили в естественных условиях при температуре не выше $+15^{\circ} \mathrm{C}$, с периодичностью проведения оценки качества 6 месяцев в течение 24 месяцев.

На основании проведенных экспериментальных исследований по вышеприведенным методикам установлены основные показатели качества салфеток с лимонника китайского семян $\mathrm{CO}_{2-}$ экстрактом, представленные в таблице 1 .

Таблица 1 - Основные показатели качества салфеток с лимонника китайского семян СО

\begin{tabular}{|c|c|c|}
\hline Показатели & Методы & Нормы качества \\
\hline Описание & Визуальный & $\begin{array}{l}\text { Салфетки нетканые влажные } \\
\text { оранжевого цвета с характерным } \\
\text { приятным запахом }\end{array}$ \\
\hline Подлинность & $\begin{array}{l}\text { Качественная реакция на флаво- } \\
\text { нолигнаны с кислотой серной } \\
\text { концентрированной } \\
\text { ТСХ в системе растворителей } \\
\text { хлороформ: спирт этиловый 95\% } \\
\text { (9:1) } \\
\\
\text { УФ - спектрофотометрия раство- } \\
\text { ра, приготовленного для количе- } \\
\text { ственного определения } \\
\text { ВЭЖХ раствора, приготовленного } \\
\text { для количественного определения }\end{array}$ & $\begin{array}{l}\text { При проявлении } 16 \% \text { р-ром кисло- } \\
\text { ты серной и активации пластинки } \\
\text { при } 100-105{ }^{0} \mathrm{C} \text { наблюдается пятно } \\
\text { желтого цвета с Rf } 0,25, \text { идентич- } \\
\text { ное схизандрину } \\
\text { УФ-спектр имеет полосы поглоще- } \\
\text { ния при } 220 \text { и } 280 \text { нм и плато при } \\
254 \text { нм. } \\
\text { Времена удерживания домини- } \\
\text { рующих пиков на хроматограмме } \\
\text { испытуемого образца совпадают с } \\
\text { временами удерживания пиков } \\
\text { стандартных образцов схизандрола } \\
\text { А и }- \text { схизандрина }\end{array}$ \\
\hline $\begin{array}{l}\text { Водородный } \\
\text { показатель (pH) }\end{array}$ & $\begin{array}{l}\text { Потенциометрическое определе- } \\
\text { ние }\end{array}$ & $6,0-7,0$ \\
\hline $\begin{array}{l}\text { Количественное } \\
\text { определение }\end{array}$ & $\begin{array}{l}\text { ВЭЖХ (схизандрол А) } \\
\text { УФ-спектофотометрия (сумма } \\
\text { лигнанов в пересчете на схизанд- } \\
\text { рол А) }\end{array}$ & $\begin{array}{l}\text { Не менее } 0,043 \% \\
\text { Не менее } 0,060 \%\end{array}$ \\
\hline
\end{tabular}

Результаты, представленные в таблице 1 , свидетельствуют о соответствии разработанной нами космецевтической формы с лимонника китайского семян $\mathrm{CO}_{2}$-экстрактом показателям качест- ва, предъявляемым к подобного рода препаратам.

Одним из важнейших показателей качества лекарственных средств является их стабильность на протяжении всего срока годности, в связи с чем, на даль- 
нейшем этапе наших исследований были проведены эксперименты по изучению стабильности и установлению сроков годности разрабатываемых салфеток. Результаты проведенных исследований представлены в таблице 2 .

Таблица 2 - Результаты определения стабильности салфеток в процессе хранения

\begin{tabular}{|c|c|c|c|c|c|c|c|c|}
\hline \multicolumn{3}{|c|}{ Показатели } & Описание & Подлинность & $\begin{array}{c}\text { Водородный } \\
\text { показатель } \\
\text { (рН) }\end{array}$ & \multicolumn{2}{|c|}{$\begin{array}{c}\text { Количественное } \\
\text { определение }\end{array}$} & $\begin{array}{l}\text { Микробиологиче- } \\
\text { ская чистота }\end{array}$ \\
\hline \multicolumn{3}{|c|}{ Методы } & $\begin{array}{c}\text { Визуаль- } \\
\text { ный орга- } \\
\text { нолептиче- } \\
\text { ский }\end{array}$ & $\begin{array}{c}\text { Качественная } \\
\text { реакция спир- } \\
\text { тового извле- } \\
\text { чения на фла- } \\
\text { вонолигнаны с } \\
\text { кислотой сер- } \\
\text { ной концентри- } \\
\text { ованной }\end{array}$ & $\begin{array}{c}\text { Потенцио- } \\
\text { метрическое } \\
\text { определение }\end{array}$ & \multicolumn{2}{|c|}{$\begin{array}{c}\text { Спектрофотомет- } \\
\text { рическое опреде- } \\
\text { ление }\end{array}$} & Диффузия в агар \\
\hline \multicolumn{3}{|c|}{ Нормы } & $\begin{array}{c}\text { Салфетки } \\
\text { нетканые } \\
\text { влажные } \\
\text { оранжевого } \\
\text { цвета с } \\
\text { характер- } \\
\text { ным прият- } \\
\text { ным запа- } \\
\text { хом }\end{array}$ & $\begin{array}{l}\text { Темно-красное } \\
\text { окрашивание }\end{array}$ & $6,0-7,0$ & \multicolumn{2}{|c|}{$\begin{array}{c}\text { Сумма лигнанов в } \\
\text { пересчете на схи- } \\
\text { зандрол А не ме- } \\
\text { нее } 0,055 \pm 0,001 \%\end{array}$} & ГФ XII, кат.2 \\
\hline \multirow{18}{*}{ 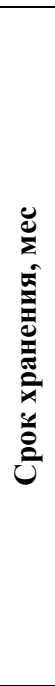 } & \multirow{6}{*}{ نَّ } & 6 & $\mathrm{y}^{*}$ & $\mathrm{y}$ & 6,2 & 0,059 & \multirow{18}{*}{ $\pm 0,001$} & $\mathrm{y}$ \\
\hline & & 12 & $\mathrm{y}$ & $\mathrm{y}$ & 6,0 & 0,059 & & $\mathrm{y}$ \\
\hline & & 18 & $\mathrm{y}$ & $\mathrm{y}$ & 6,0 & 0,059 & & $\mathrm{y}$ \\
\hline & & 20 & $\mathrm{y}$ & $\mathrm{y}$ & 6,1 & 0,058 & & $\mathrm{y}$ \\
\hline & & 24 & $\mathrm{y}$ & $\mathrm{y}$ & 6,0 & 0,059 & & $\mathrm{y}$ \\
\hline & & 26 & $\mathrm{y}$ & $\mathrm{y}$ & 6,0 & 0,046 & & $\mathrm{H} / \mathrm{y}$ \\
\hline & \multirow{6}{*}{$\frac{0}{2}$} & 6 & $\mathrm{y}$ & $\mathrm{y}$ & 6,2 & 0,059 & & $\mathrm{y}$ \\
\hline & & 12 & $\mathrm{y}$ & $\mathrm{y}$ & 6,2 & 0,058 & & $\mathrm{y}$ \\
\hline & & 18 & $\mathrm{y}$ & $\mathrm{y}$ & 6,2 & 0,058 & & $\mathrm{y}$ \\
\hline & & 20 & $\mathrm{y}$ & $\mathrm{y}$ & 6,2 & 0,058 & & $\mathrm{y}$ \\
\hline & & 24 & $\mathrm{y}$ & $\mathrm{y}$ & 6,1 & 0,058 & & $\mathrm{y}$ \\
\hline & & 26 & $\mathrm{y}$ & $\mathrm{y}$ & 6,2 & 0,054 & & $\mathrm{H} / \mathrm{y}$ \\
\hline & \multirow{6}{*}{$\overbrace{0}^{\infty}$} & 6 & $\mathrm{y}$ & $\mathrm{y}$ & 6,0 & 0,058 & & $\mathrm{y}$ \\
\hline & & 12 & $\mathrm{y}$ & $\mathrm{y}$ & 6,2 & 0,057 & & $\mathrm{y}$ \\
\hline & & 18 & $\mathrm{y}$ & $\mathrm{y}$ & 6,0 & 0,057 & & $\mathrm{y}$ \\
\hline & & 20 & $\mathrm{y}$ & $\mathrm{y}$ & 6,0 & 0,056 & & $\mathrm{y}$ \\
\hline & & 24 & $\mathrm{y}$ & $\mathrm{y}$ & 6,0 & 0,056 & & $\mathrm{y}$ \\
\hline & & 26 & $\mathrm{y}$ & $\mathrm{y}$ & 6,0 & 0,048 & & $\mathrm{H} / \mathrm{y}$ \\
\hline
\end{tabular}

*Примечание: У-удовлетворяет требованиям нормативной документации, H/y - не удовлетворяет требованиям нормативной документации

Как видно из данных, приведенных таблице 2, срок годности салфеток при хранении не выше $+15^{\circ} \mathrm{C}$, составил 24 месяца, так как при хранении, более указанного срока (до 26 месяцев), салфетки не соответствуют норме по показателям качества «Количественное определение» и «Микробиологическая чистота».

\section{Выводы}

Таким образом, экспериментально установленные нормы качества салфеток с лимонника китайского семян СО2-экстрактом могут быть рекомендованы в дальнейшем при составлении нормативной документации; предположительный срок годности салфеток с лимонника китайского семян СО2-экстрактом составляет 2 года. 


\section{Библиографический список}

1. Чехани, Н.Р. Разработка состава и технологии получения комплексного актопротекторного средства на основе растительного сырья / Н.Р. Чехани, Л.А. Павлова, В.М. Павлов // Разработка и регистрация лекарственных средств. - 2014. - № 4 (9). - С. 58-67.

2. Лебедев А.А. Лимонник.- Ташкент: «Медицина», 1971.- 114c.

3. Государственный реестр лекарственных средств [Электронный ресурс]. - Электрон. дан. (1 файл). - М., 2014. - Режим доступа: http://grls.rosminzdrav.ru/grls.aspx. (дата обращения 12.12.14).

4. Зиновьев А.И. Разработка и стандартизация адаптогенного средства и биологически активной добавки на основе растительной композиции: дис. канд. фармац. наук. Улан-Удэ, 2003. - 157 с.

5. Власов А.М. Разработка методов анализа индикаторных компонентов в фиточаях и биологически активных добавках на их основе: Автореф. дис. канд. фармац. наук. M., 2006. $-24 \mathrm{c}$.

6. Степанов А.С. Стандартизация сырья и препаратов элеутерококка колючего и лимонника китайского: дис. канд. фармац. наук. - Пермь, 2004. - 151с.

7. Сатдарова Ф.Ш. Исследования по стандартизации и созданию лекарственных средств на основе плодов и семян лимонника китайского [Schizandra chinensis (Turcz.) Baill.]: Автореф. дис. канд. фармац. наук. - Курск, 2009. - 24c.

8. Шиков А.Н., Макаров В.Г., Рыженков В.Е. Растительные масла и масляные экстракты: технология, стандартизация, свойства. М.: Издательский дом «Русский врач», 2004. $264 \mathrm{c}$.

9. Кушнерова Н.Ф. Оценка эффективности применения полифенольного комплекса из лимонника китайского // Актуальные проблемы биологии, медицины и экологии. - Владивосток, 2004. - С. 15-19.

10. К возможности использования продуктов комплексной переработки семян лимонника китайского в космецевтических препаратах / Ю.А. Морозов и др. // Фундаментальные исследования. - 2012. - № 11, Ч. 6. - С. 1492-1494.

11. Макиева, М.С. Выбор материала-носителя для оригинальных парафармацевтических форм-салфеток, содержащих лимонника китайского семян экстракт масляный / М.С. Макиева, Э.Ф. Степанова, Ю.А. Морозов // Глобализация науки: проблемы и перспективы: сб. ст. межрегион. науч.-практ. конф. 7 февраля 2014 г. - Уфа: РИЦ БашГУ, 2014. - Ч. 1. - C. 199-202.

$$
* * *
$$

Макиева Марина Сергеевна - ассистент кафедры фармацевтической химии и фармакогнозии ФГБОУ ВПО «Северо-Осетинский государственный университет имени К.Л. Хетагурова», г. Владиквказ. Область научных интересов: технология приготовления лекарств, разработка норм и оченка качества лекарственных средств. E-mail: makievamarina@yandex.ru.

Морозов Юрий Алексеевич - кандидат фармачевтических наук, дочент кафедры технологии лекарственных форм и организации фармацевтического дела ФГБОУ ВПО «Северо-Осетинский государственный университет имени К.Л. Хетагурова», г. Владикавказ. Область научных интересов: технология приготовления лекарств, трансдермальные лекарственные формы. E-mail: moroz52@yandex.ru. 